\title{
Das Ultraschallmuseum informiert!
}

Auf dem Dreiländertreffen in Stuttgart / Euroson 2013 war das Ultraschallmuseum wieder mit einem Stand vertreten. Gerade der jüngeren Generation wollen wir mit einem Film und mit Postern die Geschichte der Ultraschalldiagnostik näher bringen und mit alten noch funktionierenden Geräten sowie mit aufgeschnittenen Schallköpfen Interesse für die Anfänge des diagnostischen Ultraschalls wecken. Die Live-Demonstration mit dem Vidoson, dem ersten Real-time-Gerät der Welt aus dem Jahre 1965, war eine kleine Sensation. Mehr als 30 Kollegen versuchten die ersten sich bewegenden Bilder zu deuten.

Auch an 2 Kongress-Sitzungen beteiligte sich das Museum maßgeblich. Wir rahmten eine Laudatiositzung mit den zu ehrenden Herren G. Rettenmayer, S. Oedegaard und U. Mende historisch ein. Zum anderen organisierten wir eine Arbeitssitzung mit dem Ziel, eine History Working Group der EFSUMB zu starten. Vorerst 6 Länder stellten ihre Aktivitäten vor. Wir denken, dass sich noch weitere nationale Verbände der Idee anschließen, eine europäische Geschichte des Ultraschalls zu schreiben.

Mehr Informationen über die Aktivitäten des Museums finden Sie auf unserer Website www.ultraschallmuseum.de, dazu

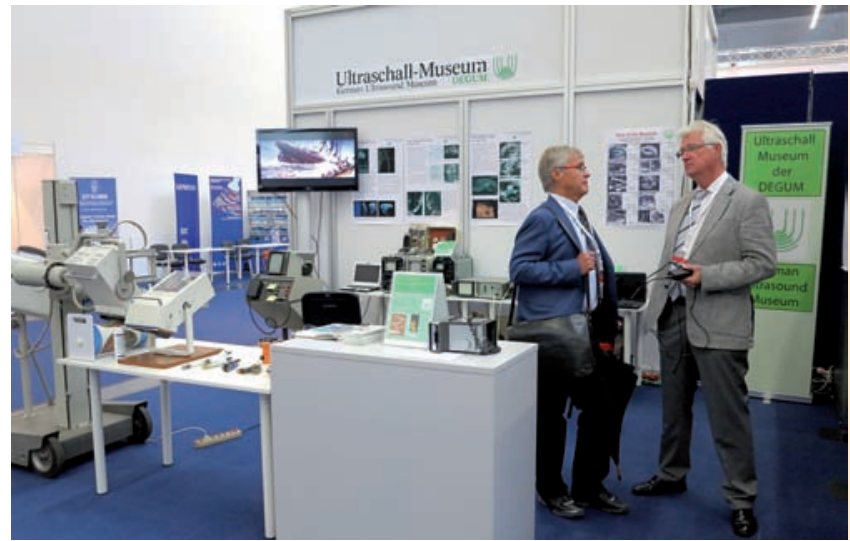

Unser Stand mit den Altmeistern H. Lutz und K. Seitz

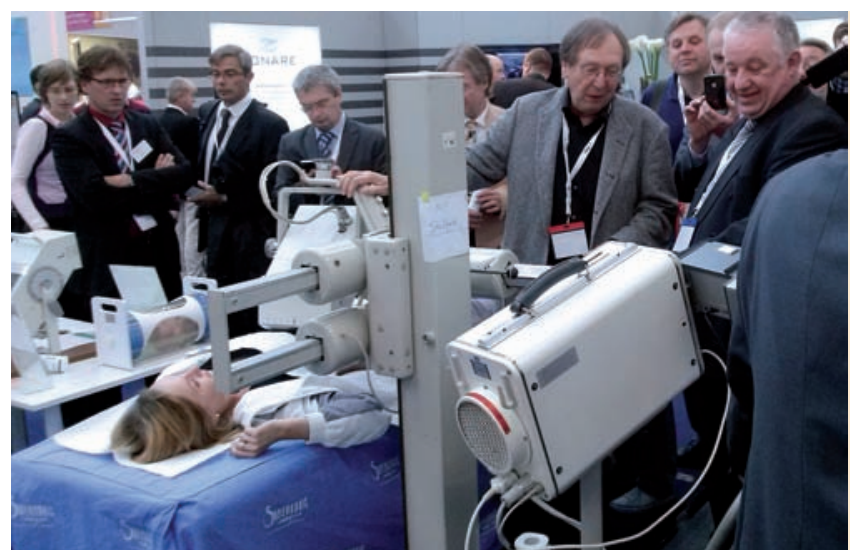

Frentzel-Beyme demonstriert das Vidoson live an einem Model.

auch ein Antragsformular (Mitgliedsbeitrag $15 € /$ Jahr).

Bernd Frentzel-Beyme 